\title{
Palaeo plant diversity in subtropical Africa - ecological assessment of a conceptual model of climate-vegetation interaction
}

\author{
V. P. Groner ${ }^{1,2}$, M. Claussen ${ }^{1,3}$, and C. Reick ${ }^{1}$ \\ ${ }^{1}$ Max Planck Institute for Meteorology, Bundesstraße 53, 20146 Hamburg, Germany \\ ${ }^{2}$ International Max Planck Research School on Earth System Modelling, Bundesstraße 53, 20146 Hamburg, Germany \\ ${ }^{3}$ Center for Earth system research and Sustainability, Universität Hamburg, Bundesstraße 53, 20146 Hamburg, Germany
}

Correspondence to: V. P. Groner (vivienne.groner@mpimet.mpg.de)

Received: 29 May 2015 - Published in Clim. Past Discuss.: 2 July 2015

Accepted: 6 October 2015 - Published: 14 October 2015

\begin{abstract}
We critically reassess a conceptual model here, dealing with the potential effect of plant diversity on climatevegetation feedback, and we provide an improved version adjusted to plant types that prevailed during the African Humid Period (AHP). Our work contributes to the understanding of the timing and abruptness of vegetation decline at the end of the AHP, investigated by various working groups during the past 2 decades using a wide range of model and palaeoproxy reconstruction approaches. While some studies indicated an abrupt collapse of vegetation at the end of the AHP, others suggested a gradual decline. Claussen et al. (2013) introduced a new aspect in the discussion, proposing that plant diversity in terms of moisture requirements could affect the strength of climate-vegetation feedback. In a conceptual model study, the authors illustrated that high plant diversity could stabilize an ecosystem, whereas a reduction in plant diversity might allow for an abrupt regime shift under gradually changing environmental conditions.

In the light of recently published pollen data and the current state of ecological literature, the conceptual model by Claussen et al. (2013) reproduces the main features of different plant types interacting together with climate, but it does not capture the reconstructed diversity of AHP vegetation. Especially tropical gallery forest taxa, indirectly linked to local precipitation, are not appropriately represented.

With a new model version adjusted to AHP vegetation, we can simulate a diverse mosaic-like environment as reconstructed from pollen, and we observe a stabilizing effect of high functional diversity on vegetation cover and precipita-
\end{abstract}

tion. Sensitivity studies with different combinations of plant types highlight the importance of plant composition on system stability, and the stabilizing or destabilizing potential a single plant type may inherit.

The model's simplicity limits its application; however, it provides a useful tool to study the roles of real plant types in an ecosystem and their combined climate-vegetation feedback under changing precipitation regimes.

\section{Introduction}

Between 9000 and 6000 years BP, a wet phase peaked across north Africa. During this so-called "African Humid Period" (AHP), large areas of the nowadays hyperarid Sahara and arid Sahel region were vegetated (Ritchie and Haynes, 1987; Prentice and Jolly, 2000), a dense fluvial network was developed, and open surface water was widespread (Hoelzmann et al., 1998). Fossil pollen records indicate that the Sahel boundary was shifted northwards by 5 to $7^{\circ}$ to at least $23^{\circ} \mathrm{N}$ (Jolly et al., 1998) and tropical plant taxa might have used river banks as migration paths to enter drier environments (Watrin et al., 2009). Vegetation cover was a diverse mosaic of xeric and tropical species whose ranges do not overlap today (Hély et al., 2014). This "greening" was triggered by changes in the Earth's orbit, resulting in a stronger insolation and higher temperatures in the boreal summer, accompanied by an intensification of the summer monsoon (Kutzbach, 1981; Kutzbach and Guetter, 1986). However, the increase in insolation alone is insufficient to explain the 
vegetation coverage reconstructed from palaeo records. It has been shown that several feedback mechanisms including ocean (Kutzbach and Liu, 1997; Braconnot et al., 1999), surface water coverage by lakes and wetlands (Coe and Bonan, 1997; Krinner et al., 2012), and vegetation and soil albedo (Claussen and Gayler, 1997; Claussen, 2009; Vamborg et al., 2011) could have amplified the orbital forcing. We here provide a conceptual model adjusted to AHP plant types as a tool to study how plant diversity as an additional parameter might have affected the climate-vegetation interaction under changing precipitation regimes.

Charney (1975) first proposed a positive feedback between vegetation and precipitation in the Sahel to explain the self-stabilization of deserts. This positive feedback provides a mechanism that might allow for the existence of multiple stable equilibria, first shown in coupled model simulations by Claussen (1994) and Claussen et al. (1998). Depending on climate and environmental conditions, the Sahara could exist in a "green" state with high vegetation cover and a "desert" state without vegetation (Brovkin et al., 1998; Bathiany et al., 2012). The potential non-linearity of this feedback might cause an abrupt transition between these states when the system reaches a "tipping point" (Williams et al., 2011). Several climate model studies reproduced such an abrupt transition from "green" to "desert" state at around 5500 years BP for western Africa (e.g. Claussen et al., 1999; Renssen et al., 2003; Brovkin and Claussen, 2008) and reconstructions of dust flux in the Atlantic supported an abrupt ending of the AHP at least for the western part of the Sahara (deMenocal et al., 2000).

Later studies highlighted the complexity of desertification history and the variety in timing and rate of regional changes. They challenged the hypothesis of an abrupt vegetation decline and doubted the existence of a strong positive climate-vegetation feedback in subtropical Africa. Pollen and sediment records from Lake Yoa in eastern Africa indicated a more gradual transition from "green" to "desert" Sahara (Kröpelin et al., 2008; Francus et al., 2013), implying that the vegetation-climate feedback was rather weak. Palaeo-hydrologically dated records from fluvial, lacustrine, and palustrine environments supported a gradual transition from wet to dry conditions (Lézine, 2009; Lézine et al., 2011). Observation based estimates of feedback strength in northern Africa showed little direct evidence of a strong positive vegetation effect on large-scale precipitation (Liu et al., 2006a). In the framework of the Paleoclimate Modeling Intercomparison Project, Phase II (PMIP2), some models even suggested a negative feedback over northern Africa for the mid-Holocene (Braconnot et al., 2007). Liu et al. (2007) demonstrated an abrupt vegetation collapse in coupled transient simulations, but the authors attributed this to a non-linear vegetation response to a precipitation threshold in the presence of strong climate variability, independent of a climate-vegetation feedback. Rachmayani et al. (2015) recently showed a positive effect of vegetation on precipitation caused by evapotranspiration effects rather than albedo effects.

Claussen et al. (2013) introduced a new aspect in the discussion, stating that plant diversity in terms of moisture requirements could affect the strength of climate-vegetation feedback. In a conceptual model study, with hypothetical discrete plant types, they demonstrated that in coupled interaction with precipitation, sensitive plant types tend to sustain longer with decreasing precipitation, while resilient plant types disappear earlier than they would do on their own. The mean vegetation coverage decreased more gradually with strong fluctuations under drying conditions, capturing the decline in pollen influx into Lake Yoa between 6000 and 4000 years BP fairly (Kröpelin et al., 2008). Plant diversity might therefore increase the stability of the climatevegetation system in semi-arid regions, buffer the strength of individual plant-precipitation feedback and prevent an abrupt vegetation collapse. The authors suggested that plant composition is of high importance for the rate of transition and a reduction in functional plant diversity may lead to an abrupt regime shift.

We critically reassess the conceptual mode by Claussen et al. (2013) here from an ecological point of view, and provide an improved version that represents the diversity of AHP plant types. Referring to the current state of knowledge in ecological literature we evaluate the representation of plantplant interaction and plant-climate feedback in the conceptual approach. We further discuss how the suggested conclusions fit in an ecological context. Based on the assessment, we adjust the original model to AHP vegetation by the modification of four fundamental aspects. First, the growth ranges in terms of moisture requirements are extended by upper limits to represent full environmental envelopes. Second, databased AHP plant types replace the hypothetical plant types. Third, the tropical gallery forest type, indirectly linked to local precipitation, follows mainly the gradual insolation forcing with a linear approximation. Fourth, we replace the dimensionless vegetation cover fraction with individual effective leaf areas to capture different contributions to climatevegetation feedback. These changes allow for studies on the roles of different real plant types in an ecosystem and their combined climate-vegetation feedback under changing environmental conditions.

\section{The conceptual approach by Claussen et al. (2013)}

\subsection{The model formulation by Claussen et al. (2013)}

The approach by Claussen et al. (2013) is based on a conceptual description of climate-vegetation feedback in semiarid regions (Brovkin et al., 1998; Liu et al., 2006b). The applicability is restricted to a region that experiences a uniform climate, which approximately corresponds to the grid size of a general circulation model (GCM) in the order of $100 \mathrm{~km}^{2}$. Within this region, the diversity of coexisting plant 
types $i=1, \ldots, N$ reflects the heterogeneity of the environment that provides ecological niches for $N$ different plant types. Diversity is defined here in terms of specific moisture requirements and sensitivities to changes in mean annual precipitation $P$. The model does not explicitly account for direct plant-plant interactions such as competition or facilitation. Claussen et al. (2013) assume that each plant type can occupy a share of $1 / N$ of the ecological space. The assumption of niche stability/conservatism - a concept that assumes species maintaining the parameters of their ecological niche following environmental change (Huntley et al., 1989; Peterson et al., 1999; Peterson, 2011; Stigall, 2012) - prohibits the replacement of disappearing plants by remaining plant types. These assumptions are hereinafter referred to as the "niche approach" (Claussen et al., 2013). The change of relative vegetation cover fraction $V_{i}$ (non-dimensional between 0 and 1) under external forcing is determined by

$\frac{\mathrm{d} V_{i}}{\mathrm{~d} t}=\frac{V_{i}^{\mathrm{E}}(P)-V_{i}}{\tau}$,

with the time step $t$ in years, setting $t=0$ for present day and negative values for the past, and the vegetation equilibrium timescale $\tau=5$ years (Liu et al., 2006b). The equilibrium vegetation cover fraction $V_{i}^{\mathrm{E}}$ is a function of mean annual precipitation $P$, and is shaped by lower and upper precipitation thresholds, $P_{i}^{C 1}$ and $P_{i}^{C 2}$, respectively. Their difference $D_{i}^{C}=P_{i}^{C 2}-P_{i}^{C 1}>0$ determines the slope of $V_{i}^{\mathrm{E}}(P)$ in the intermediate precipitation regime

$V_{i}^{\mathrm{E}}(P)= \begin{cases}1 & P \geq P_{i}^{C 2} \\ \frac{\left(P-P_{i}^{C 1}\right)}{D_{i}^{C}} & P_{i}^{C 2}>P>P_{i}^{C 1} . \\ 0 & P \leq P_{i}^{C 1}\end{cases}$

When all plant types interact together with climate, the mean vegetation cover fraction $V_{S}$ is calculated as the average of all individual plant types:

$V_{S}=\frac{1}{N} \sum_{i=1}^{N} V_{i} \leq 1$

assuming that the atmosphere reacts to the average properties of the whole area. The justification for this assumption is that the difference in crucial surface parameters such as albedo and hydrological properties is smaller between considered plant types than the contrast to desert.

Accounting for climate-vegetation feedback, precipitation is a combination of a background precipitation $P_{\mathrm{d}}$ in absence of vegetation that changes with external gradual insolation forcing, and a precipitation component induced by vegetation feedback. The equilibrium precipitation $P^{\mathrm{E}}$ is defined as

$P^{\mathrm{E}}\left(V_{S}, t\right)=P_{\mathrm{d}}(t)+D^{B} \cdot V_{S}$,

with the climate feedback coefficient $D^{B}$ that determines the feedback strength. For simplicity, Claussen et al. (2013) assumed the same $D^{B}=140 \mathrm{~mm} \mathrm{yr}^{-1}$ for all plant types (Liu

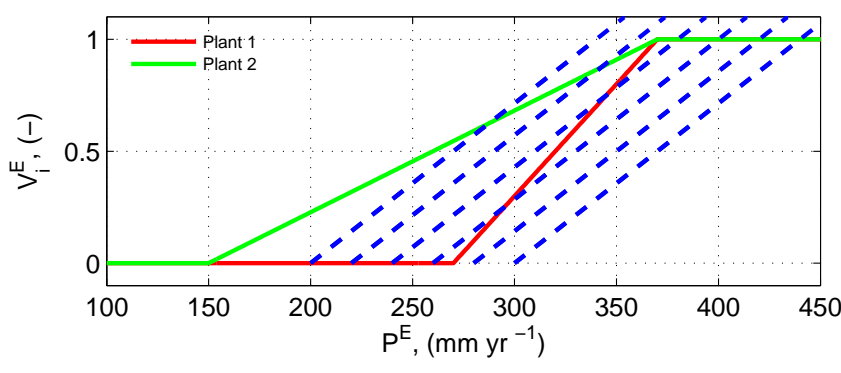

Figure 1. Vegetation-precipitation stability diagram $\left(V_{i}^{\mathrm{E}}, P^{\mathrm{E}}\right)$ for two hypothetical plant types $i=1,2$ after Claussen et al. (2013). Full lines depict the equilibrium curves for vegetation cover $V_{i}^{\mathrm{E}}\left(P^{\mathrm{E}}\right)$ for plant type 1 which is sensitive (red) and for plant type 2 which is resilient (green) to changes in precipitation. Dashed blue lines show hypothetical equilibrium precipitation curves $P^{\mathrm{E}}\left(V_{i}^{\mathrm{E}}\right)$ for different time slices $(4500,4900,5300,5700$, 6100 , and 6500 years BP, from left to right). Intersections between the two types of curves indicate equilibrium coupled states which can be stable or unstable.

et al., 2006b), implying that the feedback is only sensitive to vegetation cover but not to composition. The background precipitation $P_{d}$ changes linearly with time, mimicking the weakening of the west African monsoon due to continuous change in insolation forcing:

$P_{d}(t)=P_{d 0}(1-(t+6500) / T)$,

where $P_{d 0}=300 \mathrm{~mm} \mathrm{yr}^{-1}$ is the initial precipitation of the simulation period $T=6500$ years (Hansen et al., 2007; New and Jones, 1999). The natural variability in precipitation, independent from vegetation, is implemented as additional white noise forcing $P_{N}(t)$ in the total precipitation

$P\left(V_{S}, t\right)=\max \left(\left(P^{\mathrm{E}}\left(V_{S}, t\right)+P_{N}(t), 0\right)\right)$.

The intersections of $P$ and $V$ in a vegetation-precipitation diagram indicate equilibrium-coupled states, see Fig. 1. System instability and multiple equilibria only exist for a sufficiently strong positive vegetation feedback with $D^{B}>D_{i}^{C}$ (Liu et al., 2006b).

\subsection{Assessment of the model set up by Claussen et al. (2013)}

The basic units in the conceptual model by Claussen et al. (2013) are plant types that reflect the heterogeneity of the environment, occupying different $n$ dimensional niches. In the actual realization of plant types in the model formulation, plant diversity is only expressed in terms of different precipitation thresholds as a proxy for moisture requirements, which reduces the fundamental multidimensional niche to one portion of its climatic component. The choice of thresholds implicitly defines plants' sensitivities to changes in precipitation. Moisture requirement is an established measure to characterize diversity in recent African ecosystems (White, 
1983), and the measure is appropriate in the conceptual model because hydrology is the main determinant of plant growth in the subtropics on the considered scale of the order of $100 \mathrm{~km}^{2}$ (Coughenour and Ellis, 1993). For a more versatile description of plants' niches and the explanation of actual vegetation composition and spatial distribution within the considered region, further crucial determinants need to be taken into account. The coexistence of trees and grasses in subtropical regions and the maintenance of their ratios is a complex topic, studied for years in the framework of the "savanna question", but still not well understood (Sarmiento, 1984; Scholes and Archer, 1997; Jeltsch et al., 2000; Staver et al., 2011). The complexity arises from the many aspects involved such as mean annual precipitation, seasonality, soil type, soil moisture, surface water availability, community structure, competition, community history, and disturbances (fire, herbivory).

With the niche approach, Claussen et al. (2013) design the effective interaction between vegetation and climate from bottom up. Each plant type has specific requirements and responds individually to changes in mean annual precipitation, but the combined interaction of all considered plant types with precipitation determines and smooths the evolution of mean vegetation cover on a larger scale. This approach is supported by Williams et al. (2004) who propose that higher order features of ecosystems emerge from plants' individual responses to changing environmental conditions. Ecosystem features such as composition and physiognomy have a large impact on the exchanges of energy, moisture, aerosols, and trace gases between the land surface and atmosphere and finally on precipitation.

The niche approach also implies that once a specific plant type retreats owing to water scarcity, there may not be any other type that is able to occupy its place in the ecological space. From an ecological point of view, existing plants likely benefit from the extinction of others by having less competition and more resources available. It is questionable whether these succeeding species can occupy the niches (ecological space) of disappearing species, including their way of using resources, and overtake their ecosystem functions, or if they just occupy the available barren area (geographical space).

Apart from the diversity in moisture requirements, the variety in feedback strength and climate impact arising from the particular plant properties is not sufficiently reflected in the original model: the dimensionless potential vegetation cover and the homogeneous climate feedback coefficient $D^{B}$ mainly account for the albedo effect of the total area while inter-plant deviations in colour, reflectance properties, surface roughness, potential leaf area, and evapotranspiration capacities are neglected.

\subsection{Assessment of the interpretation of results by Claussen et al. (2013)}

Based on a number of simulations, Claussen et al. (2013) concluded that diversity can have a buffering effect on ecosystem performance and further on the strength of climate-vegetation feedback. They reasoned that in speciesrich ecosystems, the likelihood of some species being preadapted to changing environmental conditions is higher than in species poor systems. This relationship between high diversity and ecosystem stability has been debated for several decades, among other things due to the inconsistent definition of stability. We follow Pimm (1984) here, who defines stability as a twofold system property: resilience is the speed with which a community returns to a former state having been displaced from it by perturbation, while resistance is the ability to avoid such displacement. Before 1970, ecologists assumed a positive relationship between biodiversity and ecosystem stability based on simplified observations (Elton, 1958; MacArthur, 1955). This intuitive idea was questioned by May (1973), who proposed a destabilizing effect of species richness on ecosystem dynamics based on a statistical model approach with random populations. Long-term field studies on grasslands indicated a positive relation between diversity and ecosystem stability, while functional diversity seemed to be more important than the total number of species (Tilman, 1996; Tilman et al., 1997; Spehn et al., 2005). The overall opinion is nowadays that diversity might on average increase the stability of ecosystems while it serves more as a "passive recipient of important ecological mechanisms that are inherent in ecosystems" than as the driver of this positive relationship (McCann, 2000). On larger scales, extrinsic factors such as disturbance regimes and site history might become the main determinants of community stability (Sankaran and McNaughton, 1999). In the light of this, the finding of a positive diversity-stability relationship by Claussen et al. (2013) is reasonable for a region of the order of $100 \mathrm{~km}^{2}$. In connection with this relationship, Claussen et al. (2013) concluded that the stability of a climate-vegetation system can determine and arise from individual plant types' presence over longer timescales. In combined interaction with climate, sensitive plants likely grow longer than they would do on their own as they benefit from additional water and facilitation effects in a more life-sustaining environment. The duration of persistence of resilient plants is likely shortened as they suffer to a certain degree from additional competition (Brooker, 2006). This effect occurs in the model even though interactions are not explicitly modelled.

One of the main conclusions by Claussen et al. (2013) was that strong or weak climate-vegetation feedback was hard to diagnose and disentangle regarding abrupt climate changes on a regional scale. The feedback between climate and a certain plant type could be strong, but this might be capped in combination with other plant types, resulting in a gradual de- 
cline of total vegetation. Indeed, vegetation composition can play a crucial role for the ecosystem and the removal or introduction might change the system stability by changes in the ratio of individual influences (Scherer-Lorenzen, 2005). In order to keep ecosystem function stable, a minimum number of functional types is required that occupy a minimum number of niches. The addition of taxa results in a more and more complex network of interactions. While some taxa are redundant, others are irreplaceable. If these so-called "keystone species" disappear, the system might collapse. The appearance of new taxa could also interfere with networks and change energy and matter fluxes in the system, resulting in a destabilization of the ecosystem (McCann, 2000). Hence, Claussen et al. (2013) argued ecologically reasonably that it is difficult to determine the origin of system stability as the overall feedback strength depends on species composition. These difficulties are not inconsistent with previous studies that proposed strong climate-vegetation feedback, resulting in abrupt shifts from a stable "green" state to a stable "desert" state. For example, simulations by Claussen et al. (1999) were performed with the lowest possible number of PFTs, one tree and one grass. The low diversity implies a high likelihood for abrupt transitions (Scherer-Lorenzen, 2005; Claussen et al., 2013).

\section{Application of the conceptual model by Claussen et al. (2013) to AHP vegetation}

\subsection{Does the model by Claussen et al. (2013) capture the diversity of AHP vegetation?}

The approach by Claussen et al. (2013) offers a useful tool to deal with the question how diversity might affect climatevegetation interaction in semi-arid regions. However, the model reaches its limits when it comes to the application to AHP vegetation reconstructed from pollen, here referring to Hély et al. (2014). Hély et al. (2014) applied "White's classification of Africa" (1983) to palaeo-botanical proxy data from several locations in Africa and from the African Pollen Database in order to reconstruct the Holocene vegetation distribution in relation to open surface water, derived from palaeo-hydrological proxies. Pollen samples were grouped into four phytogeographical types, which are mainly characterized by their precipitation requirements and physiognomic structure: (1) Guineo-Congolian type (tropical humid semideciduous or evergreen forest taxa, > $1500 \mathrm{~mm} \mathrm{yr}^{-1}$ ); (2) Sudanian type (tropical dry forest, woodlands, and wooded savanna taxa, 500 to $1500 \mathrm{~mm} \mathrm{yr}^{-1}$ ); (3) Sahelian type (grassland or wooded grassland taxa, 150 to $500 \mathrm{~mm} \mathrm{yr}^{-1}$ ), and (4) Saharan type (steppe and desert taxa, $<150 \mathrm{~mm} \mathrm{yr}^{-1}$ ).

Throughout this paper, we use the terminology of phytogeographical plant types after Hély et al. (2014) whenever we refer to our work, including the descriptions of the adjusted model and simulations as well as results, discussions, and conclusions. Since literature often refers to the terminol- ogy of physiognomic vegetation types, we stick with their terminology in citations and indicate the corresponding phytogeographical plant types after Hély et al. (2014) in brackets to prevent confusions.

When defining the precipitation thresholds for each plant type, a direct relation between precipitation and plant available water was assumed by Claussen et al. (2013). This is not appropriate for all AHP plant types. Tropical GuineoCongolian taxa (GC type) cannot be captured with this approach using the parameters of Claussen et al. (2013) because the initial precipitation $P\left(V_{S},-6500\right)$ is too low to reach their minimum threshold $P_{\mathrm{GC}}^{C 1}$. These species grow in gallery forest or ripicolous stripes where a high water availability is more or less constantly provided, and local precipitation is of minor importance. Xeric species of the Saharan and Sahelian type have special adaptations such as deep trap roots or succulent tissues (e.g. Wickens, 1998) that allow them to grow far below the minimum threshold for a phytogeographic plant type given by literature. Nonetheless, growth ranges of phytogeographic plant types provide a point of reference, and expose the fact that the range of precipitation thresholds assumed by Claussen et al. (2013), between 150 and $370 \mathrm{~mm} \mathrm{yr}^{-1}$, is far below the variety of thresholds of AHP vegetation reconstructed from pollen (Hély et al., 2014).

Regarding the calculation of mean vegetation with the niche approach, climate-vegetation interaction provides the expected gradual decline in mean vegetation cover towards the end of the AHP. Niches can only be occupied by specialized plant types, for instance gallery forests (GC) cannot grow beyond a certain distance from surface water while steppe plants (Saharan type) do not survive on moist soils along river banks. However, the niche approach does not account for the evolution of vegetation composition in terms of spatial succession. Pollen data from eastern Africa suggest the decrease in tropical trees and grasses (GC and Sudanian type) starting at around $5500 \mathrm{cal}$ yr BP going hand in hand with the expansion of characteristic desert taxa (Saharan type). The demise of tropical trees (GC and Sudanian type) was temporarily compensated by Sahelian elements (Kröpelin et al., 2008). For the geographically explicit simulation of vegetation change, a model more sophisticated than our conceptual approach is required.

The large diversity of plant properties besides moisture requirements highlights the importance of plant-specific feedback strengths. With a dimensionless vegetation cover fraction, Claussen et al. (2013) mainly account for a homogeneous albedo. Differences in colour and reflectance properties are not implemented. Generally, tropical leaves (GC and Sudanian type) are darker than steppe grasses (Saharan type) (White, 1983) and their albedo-feedback impact should be weighted differently. Structural properties are homogenized, assuming the same feedback coefficient for all plant types. The leaf area of tropical taxa (GC and Sudanian type) might be up to 3 times higher than that of steppe taxa (Saharan type) 
(Hély et al., 2009), resulting in strong evapotranspiration differences. Evapotranspiration seems to be involved in important feedback mechanisms that influence the strength of the west African monsoon (Rachmayani et al., 2015).

In summary, the original conceptual model by Claussen et al. (2013) seems to capture the stabilizing effect on ecosystem performance by accounting for differential moisture requirements and homogeneous feedback for all plant types. Important determinants of vegetation cover, such as fire or competition, and individual feedback strengths due to albedo and evapotranspiration differences are omitted. The diversity of AHP vegetation reconstructed from pollen data cannot be captured; especially tropical gallery forest plant types (GC type) are not represented.

\subsection{Model adjustment}

In order to apply the conceptual model by Claussen et al. (2013) to AHP vegetation, we modify different aspects as described in the present section.

The environmental envelopes in terms of moisture requirements are extended by an upper precipitation threshold. Data-based AHP plant types are implemented, namely the Saharan type, Sahelian type, Sudanian type, and GuineoCongolian type. Specific tolerance threshold values for these plant types, except for the Guineo-Congolian gallery forest type, are derived from observations on characteristic species (see Table 1), implicitly accounting for competitive interactions and fire that cannot be separated from water constraints. The optimum growth ranges are based on pollen analysis by Hély et al. (2014). The relative vegetation cover fraction (initially $V_{i, \max }=1$ ) is replaced by a weighting factor modelled after the leaf area index. This effective leaf area $L_{i}$ (in $\mathrm{m}^{2}$ per unit niche area) of each plant type $i$ changes according to $V_{i}$ in Eq. (1). In equilibrium, $L_{i}^{\mathrm{E}}$ is specified as a function of total precipitation $P$ :

$$
L_{i}^{\mathrm{E}}(P)= \begin{cases}0 & P \geq P_{i}^{C 4} \\ L_{i, \max }-\frac{\left(P-P_{i}^{C 3}\right) \cdot L_{i, \max }}{D_{i}^{C 2}} & P_{i}^{C 4}>P \geq P_{i}^{C 3} \\ L_{i, \max } & P_{i}^{C 3}>P \geq P_{i}^{C 2}, \\ \frac{\left(P-P_{i}^{C 1}\right) \cdot L_{i, \max }}{D_{i}^{C 1}} & P_{i}^{C 2}>P \geq P_{i}^{C 1} \\ 0 & P<P_{i}^{C 1}\end{cases}
$$

with a maximum potential extension $L_{i, \max } \cdot D_{i}^{C 1}=P_{i}^{C 2}-$ $P_{i}^{C 1}>0$ for the increasing branch and $D_{i}^{C 2}=P_{i}^{C 4}-P_{i}^{C 3}>$ 0 for the decreasing branch of the environmental envelope. For simplicity, we aggregate all surface parameters crucial for climate-vegetation feedback - leaf area, albedo, and hydrological properties - in $L_{i}$, and keep the climate feedback coefficient $D^{B}$ constant for all plant types. This is possible because $L_{S}$ and $D^{B}$ show up as a product in our model (see Eq. 11). Values for $L_{i, \max }$ are chosen to qualitatively represent the variety of these aggregated properties following observation-based classifications (Hély et al., 2006, 2009).
A high $L_{i}$ also indicates a dark leaf colour, characteristic for tropical taxa (GC and Sudanian type), which is related to a low albedo, a strong climate-feedback, and a potentially abrupt collapse. A lower $L_{i}$ represents dry bright leaves, characteristic for xeric taxa (Saharan and Sahelian type), and is associated with a low albedo feedback potential. The differences between considered plant types might be smaller than the contrast to desert, but investigating individual roles necessitates disentangling the contributions.

The Guineo-Congolian plant type cannot be captured with this approach as the initial precipitation $P\left(V_{S},-6500\right)$ is too low to reach its minimum threshold $P_{\mathrm{GC}}^{C 1}$. This tropical plant type grows in gallery forest or ripicolous stripes where a high water availability is more or less constantly provided. Local precipitation is less important than the large-scale climate which is assumed to be determined by orbital forcing. In order to account for this special relation to water availability, the effective leaf area $L_{\mathrm{GC}}^{\mathrm{E}}$ of this plant type is prescribed with a linear approximation, following the gradual insolation forcing and $P$ :

$L_{\mathrm{GC}}^{\mathrm{E}}(t, P)=-a-\frac{1}{b} \cdot t+c \cdot P$.

The parameters $a, b$ and $c$ are tuned such that $L_{\mathrm{GC}}^{\mathrm{E}}=0.5$ for $P=500 \mathrm{~mm} \mathrm{yr}^{-1}$ because gallery forests potentially cover only a small fraction of semi-arid regions and play therefore only a limited role in climate-vegetation feedback, and $L_{\mathrm{GC}}^{\mathrm{E}}=0$ for $t=-3000$ because this is the timing of disappearance reconstructed from pollen (Hély et al., 2014).

The effective leaf area $L_{S}$ of all plant types together is unconstrained and calculated with the niche approach:

$L_{S}=\frac{1}{N} \sum_{i=1}^{N} L_{i}$

For sensitivity studies on the role of plant composition and the effect of introducing or removing single functional plant types, $L_{S}$ is calculated with a modified version of the niche approach

$L_{S}=\frac{1}{n} \sum_{i=1}^{N} L_{i}, \quad N \leq n$,

where $n$ is the number of existing niches that can be occupied by $N$ different plant types. This calculation implies the lack of relevant ecosystem functions when a niche is not occupied. We use $n=N+1$ in our simulations.

The total precipitation is calculated in an analogous manner to Claussen et al. (2013) (see Eq. 5) as a combination of a background precipitation $P_{\mathrm{d}}$ in absence of vegetation, and a precipitation component induced by vegetation feedback

$P^{\mathrm{E}}\left(L_{S}, t\right)=P_{\mathrm{d}}(t)+D^{B} \cdot L_{S}$,

with a constant climate feedback coefficient $D^{B}=$ $140 \mathrm{~mm} \mathrm{yr}^{-1}$ (Liu et al., 2006a; Claussen et al., 2013). 
Table 1. Precipitation thresholds $P_{i}^{C 1}$ to $P_{i}^{C 4}$ (in $\mathrm{mm} \mathrm{yr}^{-1}$ ) and maximum effective leaf area $L_{i, \text { max }}$ (in $\mathrm{m}^{2}$ per unit niche area) for the African Humid Period (AHP) plant types: Saharan type, Sahelian type, and Sudanian type.

\begin{tabular}{llll}
\hline & Saharan type & Sahelian type & Sudanian type \\
\hline$P_{i}^{C 1}$ & 0 & 20 & 150 \\
& absolute minimum & $\begin{array}{l}\text { Acacia tortilis } \\
\text { Baumer et al. (1983) }\end{array}$ & $\begin{array}{l}\text { Celtis integrifolia } \\
\text { Le Houérou (1980) }\end{array}$ \\
\hline$P_{i}^{C 2}$ & 100 & 150 & 500 \\
& Saharan desert boundary & Hély et al. (2014) & Hély et al. (2014) \\
& 100 mm isohyet & & \\
& Wickens (1998) & & 1500 \\
\hline$P_{i}^{C 3}$ & 150 & 500 & Hély et al. (2014) \\
& Hély et al. (2014) & Hély et al. (2014) & $\begin{array}{l}\text { 1800 } \\
\text { Pterocarpus erinaceus }\end{array}$ \\
\hline$P_{i}^{C 4}$ & 600 & 900 & Le Houérou (1980) \\
& Ziziphus mauritiana & Balanites aegyptiaca & Baumer et al. (1983) \\
\hline$L_{i, \text { max }}$ & Le Houérou (1980) & 2 & 3 \\
\hline
\end{tabular}

Results from sensitivity studies on $D^{B}$ ranging from 0 to $150 \mathrm{~mm} \mathrm{yr}^{-1}$ are provided in the Supplement. The initial background precipitation is set to $P_{d 0}=500 \mathrm{~mm} \mathrm{yr}^{-1}$ which supports an average woody fraction of around $80 \%$, based on observational data (Hansen et al., 2007; New and Jones, 1999), the potential maximum cover in climate-driven savannas (Sankaran et al., 2005). The natural variability in precipitation, independent of vegetation, is implemented as additional white noise forcing $P_{N}(t)$ in the total precipitation

$P\left(L_{S}, t\right)=\max \left(\left(P^{\mathrm{E}}\left(L_{S}, t\right)+P_{N}(t), 0\right)\right)$.

\subsection{Results from the adjusted model}

The environmental envelopes for the four AHP plant types are shown in Fig. 2. Upper and lower precipitation thresholds mark the growth ranges based on moisture requirements, the limiting and therewith determining factor for plant growth in semi-arid regions (Shelford's law of tolerance 1913). Since thresholds are derived from empirical relationships between observed species distributions and environmental variables, the implemented envelopes correspond to the "realized niches" or "climatic niches" that are narrower than the potential "fundamental niches" of plant types, as they implicitly account for further abiotic and biotic constraints (Hutchinson, 1957; Pearman et al., 2008). This constrains the comparison between plants interacting individually or together with climate.

In our implementation of the vegetation types described by Hély et al. (2014), plant types range from xeric desert shrubs and grasses $\left(<150 \mathrm{~mm} \mathrm{yr}^{-1}\right)$ to large tropical trees $(>$ $1500 \mathrm{~mm} \mathrm{yr}^{-1}$ ). Biome sensitivity assessment studies support this setup of plant sensitivities, suggesting that the percentage of rainfall decrease necessary to shift from one

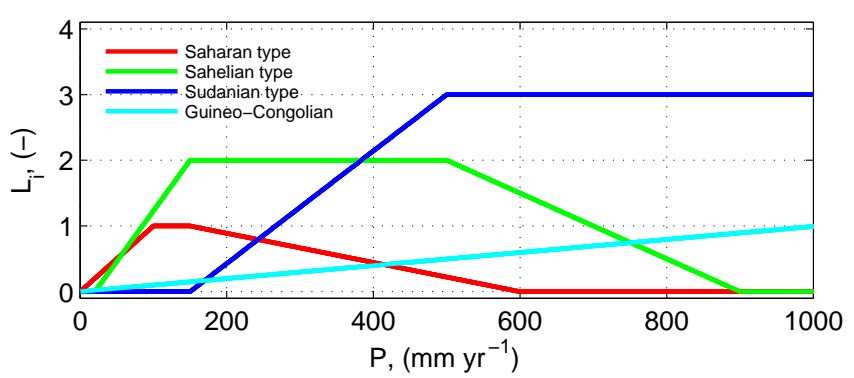

Figure 2. Environmental envelopes in terms of moisture requirements of four African Humid Period (AHP) plant types in the adjusted set up. The effective leaf area $L_{i}$ is plotted as a function of mean annual precipitation $P$ for the Saharan type (red), Sahelian type (green), Sudanian type (blue), and Guineo-Congolian type (light blue).

biome to another seems to be lowest for deciduous forests, followed by semi-deciduous forest, evergreen forest, grasslands, open and finally closed savannas (Hély et al., 2006). It is not clear whether gallery forests are as sensitive to decrease in rainfall as other forest types. Once being established in savannas, positive feedback effects may come into play and stabilize their expansion (Silva et al., 2008). The sensitivities of these plant types to changing environmental conditions are represented by the slopes of the curves in Fig. 2 . Saharan and Sahelian plant taxa are mainly drought-adapted species that survive until conditions become very harsh, and they respond quickly if precipitation occurs. The Sudanian type includes herbaceous and woody savanna taxa that grow under a wide range of conditions, so the gradual decline with decreasing precipitation seems reasonable. The prescription of the Guineo-Congolian tropical gallery forest plant type as 
a linear function of the orbital forcing and local precipitation with relatively low $L_{\mathrm{GC} \text {, max }}$ accounts for internal stability.

The effective leaf area $L_{i}$ introduces an additional degree of freedom in the model, acting as a weighting factor for each plant type in the combined interaction with climate. All surface parameters crucial for climate-vegetation feedback - leaf area, hydrological properties, and albedo - merge in $L_{i}$. Tropical plants, especially trees, usually achieve higher leaf areas and higher evapotranspiration rates than grasses or other steppe vegetation. Higher evapotranspiration has in turn a larger impact on atmospheric processes and the formation of precipitation than the low leaf area of steppe vegetation.

Simulations of AHP vegetation interacting individually and together with climate, and the corresponding precipitation curves, are shown in Fig. 3. Except for the GuineoCongolian type, all plant types show an abrupt decline and a pronounced hysteresis effect when they interact individually with climate (Fig. 3a). This low stability results from the strong chosen climate feedback coefficient of $140 \mathrm{~mm} \mathrm{yr}^{-1}$. The corresponding precipitation curves go in conjunction with the abruptness of $L_{i}$ decline (Fig. 3c). In single interaction with climate, the Guineo-Congolian type declines linearly until it disappears at around year -3000 . The Sudanian type starts with $L_{\text {Sudanian, } \max }=3$ and collapses abruptly at around year -3600 due to the strong feedback. It develops a hysteresis of around 500 years. The Sahelian type starts with $L_{\text {Sahelian }}$ of around 1.2, reaches $L_{\text {Sahelian, } \max }=2$ at year -4600 and collapses abruptly at around year -2200 . It develops a hysteresis of around 1000 years. The Saharan type gradually increases from an initial $L_{\text {Saharan }}$ of around 0.1 to $L_{\text {Saharan, } \max }=1$ at around year -3200 , before it collapses at around year -2900 . It develops a hysteresis of around 300 years.

When all plant types interact together with climate, we observe more gradual responses to the orbital forcing, changes in appearance over time, and the almost complete disappearance of hysteresis effects (Fig. 3d-e). This can be interpreted as an enhancement of system stability (Scheffer et al., 2001). The precipitation curve resulting from feedback with $L_{S}$ shows a smooth decline (Fig. 3f). In combined interaction with the other plant types, the Guineo-Congolian type starts with a higher $L_{\mathrm{GC}}$ than alone because this type benefits from local precipitation. The appearance over time does not change as orbital forcing surpasses the beneficial effect from local precipitation enhancement. A high potential effective leaf area puts the Sudanian type in a dominant position in the multi-niche system. $L_{\text {Sudanian }}$ starts to decline 1500 years earlier than on its own, but it finally disappears after a more gradual decline around 200 years later than alone. Hence, its abundance is reduced over time due to the presence of other plant types, while its absolute appearance over time is extended. The hysteresis almost disappears. The decline of the Sahelian type starts 1100 years earlier in the combined interaction, happens more gradually and ends around
1000 years earlier than alone. The period of maximum abundance is shifted deeper in the past and the absolute appearance over time is shortened in the considered time frame. The hysteresis almost disappears. The Saharan type starts in combined interaction from $L_{\text {Saharan }}=0$, increases gradually from year -6000 to its full potential cover at around year -3500 before it disappears again between year -3300 and -3200 . The time span of maximum abundance as well as the total appearance over time are reduced due to the presence of the other plant types. The hysteresis almost disappears. The Saharan type is largely outcompeted by other plant types in higher precipitation regimes. It only succeeds in the short period of low precipitation amounts.

Under the assumption of a full environmental envelope, the niche approach gives reasonable results for $L_{S}$ regarding functional diversity. The evolution of $L_{S}$ can be divided into three main phases (Fig. 3e). At the beginning of the simulation, $L_{S}$ is not at its maximum which could be explained in consideration of the physiognomic community structure in reality. Under a high precipitation regime, the Sudanian type has the largest share of vegetation, including many tree species that outcompete undergrowth. With decreasing precipitation in the first phase from year -6500 to -5200 , tree cover and therewith ground shading effects are reduced and it becomes easier for undergrowth species to establish. While the composition changes substantially under decreasing precipitation, $L_{S}$ only increases by 0.2 . In the second phase between year -5200 and $-3400, L_{S}$ slowly decreases by 0.3 , slightly below the initial level of 1.1. With the total disappearance of the Sudanian type at around year -3400 , the third phase is initiated and therewith a steeper and fluctuating, but still gradual transition to a desert state. The system has now simplified to just two plant types and those are nearing their thresholds, which causes the increase in fluctuations. The increase in fluctuations is one of the proposed early warning signals for regime shifts (Scheffer et al., 2001, 2009). After year -3000 , vegetation is completely absent.

Stepping back to the reconstructions by Hély et al. (2014), our simulations show an evolution of plant diversity similar to reconstructions north of $20^{\circ} \mathrm{N}$. Hély et al. (2014) proposed that all these plant types were present around year -6000 , diversity was highest in and within plant types, and tropical types (Guineo-Congolian and Sudanian type) reached their maximum extension and abundance. After year -6000 , pollen abundance and diversity decreased for all plant types. Tropical types apparently declined in conjunction with latitudinal humid surfaces as they grew mainly in gallery forests. Regarding the abundance of pollen in Hély et al. (2014), vegetation was completely absent after year -3000 north of $20^{\circ} \mathrm{N}$. All these observations are also true for our simulations, except for the lack of the Saharan type in the beginning of our simulations in year -6000 due to the assumed low maximum precipitation threshold. Quantitative comparison between Hély et al. (2014) and our simulations is not possible because their reconstructions rely on pollen rich- 

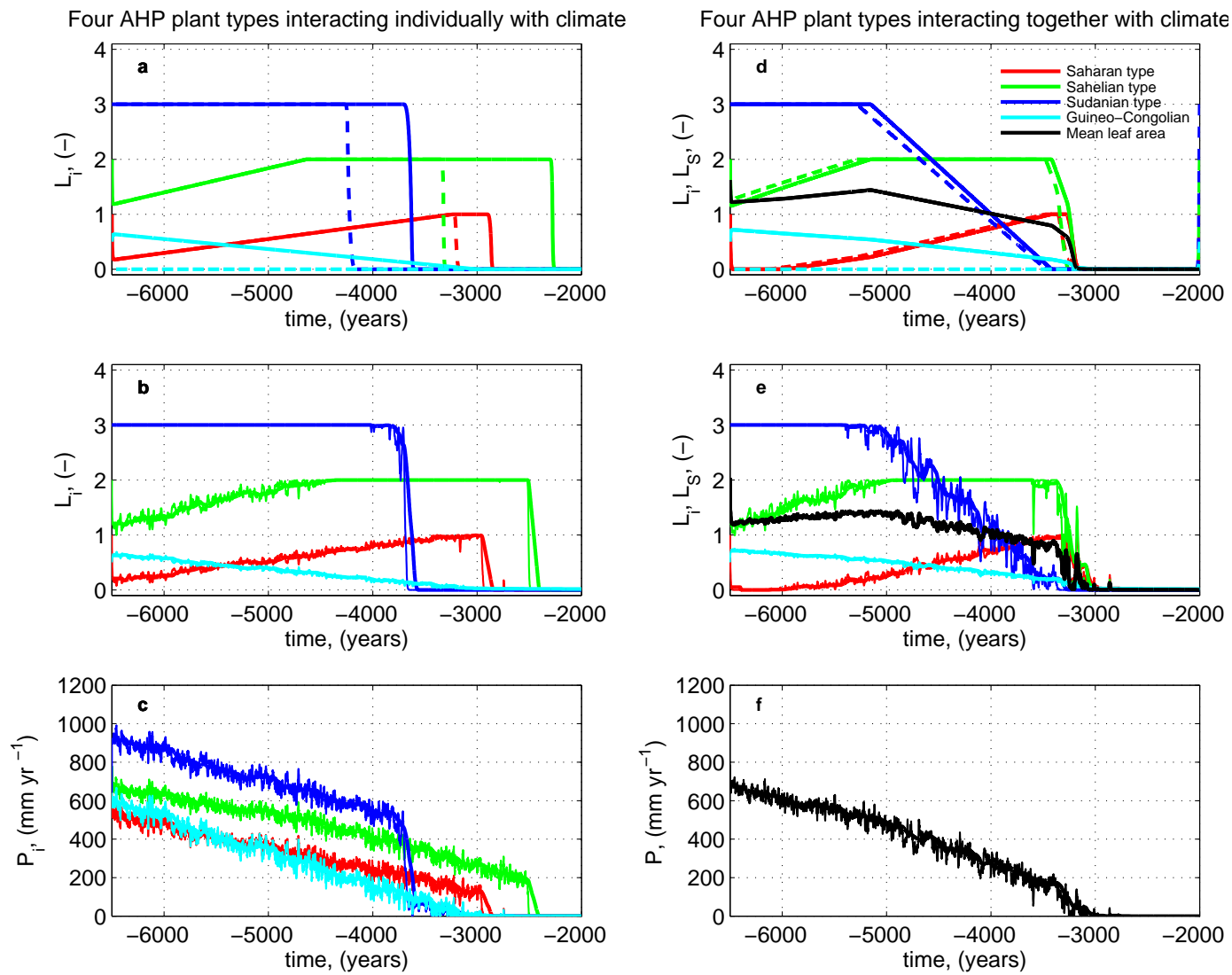

Figure 3. Transient dynamics of four African Humid Period (AHP) plant types interacting individually (a-c) and together (d-f) with climate. The effective leaf areas $L_{i}$ and the corresponding precipitation amounts $P_{i}$ are shown for the Saharan type (red), Sahelian type (green), Sudanian type (blue), and Guineo-Congolian type (light blue). Mean effective leaf area $L_{S}$ and the corresponding precipitation $P$ are calculated with the niche approach (black) (see Eq. 9). Simulations without background noise (a, e) include forward simulations (solid lines) and simulations backward in time (dashed lines). Simulations with background noise are depicted in (b, e) for $L_{i}$ and $L_{S}$, and for precipitation $P$ in $(\mathbf{c}, \mathbf{f})$. Thin lines show annual mean values and thick lines show a 100 year running mean.

ness and abundance while we consider the area of growth. High richness and abundance of individual types should not be equated with high plant cover.

So far, we have considered the interaction of AHP plant types interacting individually or all together with climate. We now address the role of plant composition and completeness of required functional types. Claussen et al. (2013) stated that climate-vegetation feedback strength could change if certain plant types were removed or introduced by some external forcing.

Our simulations with different combinations of plant types highlight the importance of plant composition on system stability, but we can only make qualitative statements about different scenarios. Figure 4 shows $L_{S}$ computed from Eq. (10) with different combinations of plant types. In each simulation, one plant type is absent and its niche is not occupied. The removal of tropical plant types tends to enhance the fluctuations and steepness of the transition while the lack of drought-adapted plant types causes a more gradual decline that starts earlier. It is not possible to determine with the conceptual approach used here if one of the considered plant types actually played a key role for the stability of the climate-vegetation system during the mid-Holocene, but the Sudanian type seems to have a large impact on our simulations. This is mainly because the Sudanian type was prescribed the highest potential effective leaf area, and its removal leaves the interaction with climate to the Saharan and the Sahelian type, which are both sensitive to changes in precipitation and respond abruptly when their minimum thresholds $P_{i}^{C 1}$ are crossed. Nonetheless, we show that there might be large differences in the mean cover over time depending on the involved plant types, the overlap of environmental envelopes, and the individual response to changing conditions.

\subsection{Limitations of the adjusted model}

The adjustment of the model by Claussen et al. (2013) to AHP plant types reconstructed from pollen (Hély et al., 2014) improves the representation of plant diversity during the mid-Holocene and provides a tool to investigate the im- 

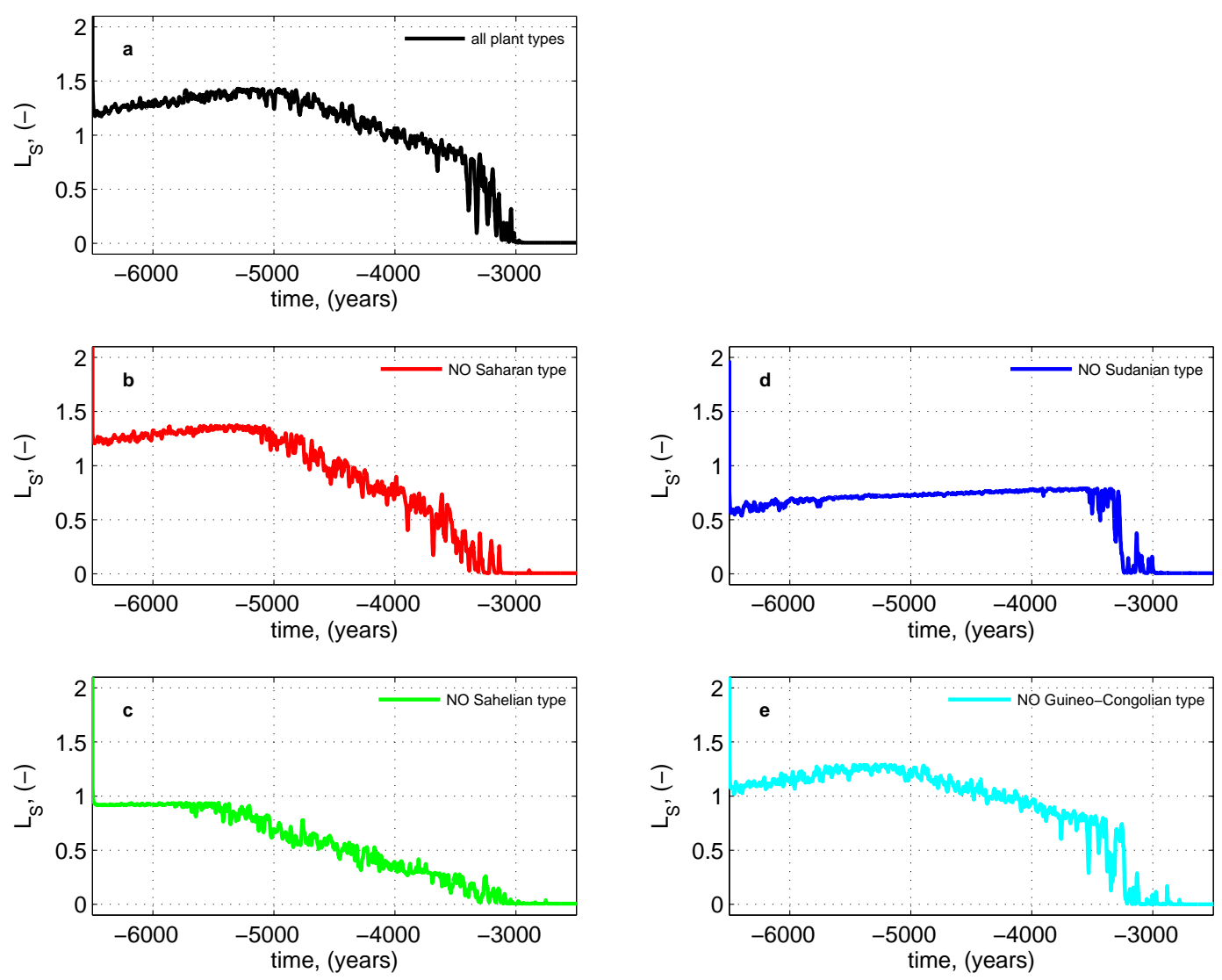

Figure 4. Transient dynamics of mean effective leaf area $L_{S}$ illustrate the impact of the removal of plant types. Panels (a-e) show 100 year running means of different simulation set ups. The mean effective leaf area $L_{S}$ accounting for all plant types $(N=n=4$ in Eq. 10) is shown as a reference (a). In each of the other simulations, one niche is not occupied ( $N=3$ and $n=4$ in Eq. 10): no Saharan type (b), no Sahelian type (c), no Sudanian type (d) or no Guineo-Congolian type (e).

pact that different plant types might have on the stability of a climate-vegetation system. Nonetheless, the model's simplicity limits its application.

As mentioned in Sect. 2.2, moisture requirement is an established measure to characterize diversity in recent African ecosystems. However the measure is insufficient to describe plants' niches and to explain actual vegetation composition and spatial distribution within the considered region, because determinants other than precipitation amounts are not taken into account. We do not explicitly implement additional plant growth determining parameters in the adjusted model, but moisture requirements from empirical data implicitly account for such additional factors. Niches in the model describe "realized niches", and contributions of determinants such as fire or competition for nutrients cannot be separated from the difference in water requirements. This complicates the comparison between plant types interacting individually or together with climate because the actual simulation of individual growth is not possible. Nonetheless, water is the limiting factor in subtropical Africa and the effects of additional or reduced precipitation due to the presence of other plant types can be considered with our model.
Another shortcoming is the merging of all surface parameters crucial for climate-vegetation feedback - leaf area, albedo, and hydrological properties - in $L_{i}$. The individual importance of each of these parameters regarding the effect on atmospheric dynamics and precipitation patterns varies over different latitudes in subtropical Africa (Bathiany et al., 2014): in the Sahara, an increase in plant growth results in a net warming because the surface heating due to albedo decrease surpasses the increase of latent heat flux; the Sahel experiences a net cooling with additional vegetation because evapotranspiration cooling exceeds the albedo warming effect; south of the Sahel, where tree cover and water availability are generally high, the stomatal resistance limits the latent heat flux which results in a net warming. This heterogeneous pattern makes an individual consideration of feedback determinants important, but cannot be performed with our approach as contributions enter the product of $L_{S}$ and $D^{B}$ which makes disentangling impossible.

The same applies to the assumption of a homogeneous feedback coefficient $D^{B}$ for all plant types which does not account for diversity in feedback strength, but it could not be separated from the product with $L_{S}$ anyway. Another short- 
coming of $D^{B}$ is its arbitrary choice to force strong feedback and abrupt state transition (Liu et al., 2006a). Quantitative estimates of the climate feedback coefficient $D_{i}^{B}$ based on remote sensing observations of monthly fraction of photosynthetically active radiation show on average a positive feedback on precipitation in the Saharan region, values range in subtropical Africa from -60 to $120 \mathrm{~mm} \mathrm{yr}^{-1}$, but little evidence of strong vegetation-precipitation feedback (Liu et al., 2006a). Sensitivity studies with various combinations of $D_{i}^{B}$ show only minor changes in the evolution of $L_{S}$ over time (see Supplement).

\section{Summary and conclusions}

In the scope of this paper, we critically reassess the conceptual model by Claussen et al. (2013) in the light of recent ecological literature, and provide an improved version that accounts for plant diversity during the African Humid Period (AHP) as it was reconstructed from pollen by Hély et al. (2014).

Despite its simplicity, the original conceptual model by Claussen et al. (2013) seems to capture the main features of different plant types interacting together with climate, namely the enhancement of climate-vegetation system stability. The underlying assumptions are reasonable in an ecological context concluded from literature.

The definition of diversity in terms of moisture requirements is an established and appropriate approach for semiarid regions because precipitation is the main determinant of plant growth there. Neglecting further crucial factors for vegetation composition and distribution such as fire or competition is therefore reasonable in the simple approach.

With the niche approach, the effective feedback between vegetation and climate emerges from the interacting properties of different plant types fulfilling specific ecosystem functions. Once a plant type disappears as precipitation drops below the requirements, other plant types cannot occupy its niche (ecological space). The prohibition of replacement depicts the fundamental ecological niche in its original sense, but the approach does not allow for a geographically explicit description of vegetation cover evolution. Further, the changes in niches available for occupation that result from substantial changes in the environment over millennia are not implemented.

Regarding the interpretation of transient simulations, the conclusions made by Claussen et al. (2013) fit in the ecological state of knowledge. After decades of debating, ecologists nowadays agree that biodiversity can have a stabilizing effect on ecosystems, especially under changing environmental conditions (see Sect. 2.3). Claussen et al. (2013) concluded that the stability of a climate-vegetation system can determine and arise from plants' appearance over time. Sensitive plants likely benefit from additional water and facilitation effects in a more life-sustaining environment, whereas resilient plants might suffer to a certain degree from additional competition. Claussen et al. (2013) argued ecologically reasonably that it is difficult to determine the origin of system stability as the overall feedback strength depends on species composition. These difficulties are not inconsistent with previous studies that proposed strong climate-vegetation feedback, resulting in abrupt shifts from a stable "green" state to a stable "desert" state. Simulations by Claussen et al. (1999) were performed with the lowest possible number of PFTs, one tree and one grass. The low diversity implies a high likelihood for abrupt transitions (Scherer-Lorenzen, 2005; Claussen et al., 2013). In previous studies that focused on multiple stable states of the climate-vegetation system in north Africa, including those of Claussen et al. (1998), Liu et al. (2006a), and Bathiany et al. (2012), it was argued that an abrupt change emerging from the loss of stability of one of the stable climate-vegetation states causes abrupt changes in both the vegetation record and the hydroclimatic record. Our study, however, supports the hypothesis of Claussen et al. (2013) that in an ecosystem with rich plant diversity, multiple stable states can exist, even if the hydroclimate record shows a gradual transition. Hence the latter studies do not invalidate the earlier considerations.

When it comes to the application to AHP vegetation reconstructed from pollen data (Hély et al., 2014), the model by Claussen et al. (2013) reaches its limits. The diversity of AHP vegetation in terms of moisture requirements and climate impact cannot be captured. The direct relation between precipitation and plant cover does not hold for highly specialized xeric plant types or tropical plant types indirectly linked to regional precipitation, and the diversity of feedback strength and climate impact arising from different plant properties is not sufficiently reflected in the original model.

Our modifications refine the model setup and account for a more realistic spectrum of plant types, interactions, and feedbacks. The extension of environmental envelopes enables coexistence and superseding of different plant types when conditions and the set of available niches change. The implementation of the vegetation types described by Hély et al. (2014) provides an insight into plant diversity during the AHP. Plant types range from xeric desert shrubs and grasses to large tropical trees. Since precipitation thresholds are derived from observational data, abiotic and biotic constraints cannot be completely separated. Together with the full environmental envelopes, the prescribed retreat of tropical gallery forest taxa allows for the representation of a mosaic like spatial environment as it was reconstructed from pollen. The effective leaf area introduces an additional degree of freedom that acts as a weighting factor for each plant type in the combined interaction with climate, accounting for differences in leaf area, albedo and hydrological properties.

Simulations with the adjusted model version support the stabilizing effect of functional diversity on ecosystem performance and precipitation proposed by Claussen et al. (2013), but provide more details on plant turnover. When all plant 
types interact together with climate, we observe rather gradual responses to decreasing precipitation, changes in appearance over time and the almost complete disappearance of hysteresis effects. Over a period of around 3100 years, the mean cover varies little while composition changes completely. The disappearance of tropical types initiates the final steeper and fluctuating, but still gradual, transition to a desert state within 400 years. After year -3000 , vegetation is completely absent. The temporal evolution of plant types compares well with reconstructions by Hély et al. (2014) north of $20^{\circ} \mathrm{N}$.

The importance of plant composition for the stability of a climate-vegetation system becomes clear comparing different combinations of plant types. Apparently, the Sudanian type played a leading role for the stability of the climatevegetation system, but we cannot determine if one of the considered plant types actually played a key role during the mid-Holocene with our model. Nonetheless, we can show that there might be large differences in the mean cover over time depending on the involved plant types, occupied niches and their overlap, and the individual sensitivities to changing conditions.

For further studies on the effect of plant diversity on the stability of climate-vegetation systems, we propose not to complicate the conceptual model any further by introducing more ad hoc tunable parameters, but to transfer the lessons learned from this study to a comprehensive dynamic vegetation model.

Our Earth system model MPI-ESM did not show abrupt transitions of large-scale vegetation cover in previous transient Holocene simulations, and the understanding we gained in this study can help to investigate whether this is an effect emerging from the representation of diversity in our land surface model JSBACH. This process-based model offers the possibility to represent different degrees of plant diversity in various plant properties, and a variety of interactions with the atmosphere to address the arising question: could a more complex model depict AHP plant diversity and reproduce the results from our qualitative conceptual study? Would changes in plant diversity stabilize or destabilize the climate vegetation system in coupled GCM simulations? Could new PFTs designed after pollen reconstructions better represent plant diversity in subtropical Africa? Could the implementation of additional processes in JSBACH, such as root competition or light competition, or additional plant properties, such as fire-resistance, lead to new effects on the climatevegetation system stability?

In summary, a deeper understanding of the role that plant diversity can play in climate-vegetation interaction, and an improved representation of plant diversity based on pollen reconstructions, could allow for a more realistic consideration of plant-plant interaction and climate-vegetation feedback in coupled GCM simulations.

\section{The Supplement related to this article is available online at doi:10.5194/cp-11-1361-2015-supplement.}

Acknowledgements. Thanks to Jochem Marotzke and Dallas Murphy for their expert advice and support in scientific writing, and to Gitta Lasslop for review and fruitful discussions.

The article processing charges for this open-access publication were covered by the Max Planck Society.

Edited by: J. Guiot

\section{References}

Bathiany, S., Claussen, M., and Fraedrich, K.: Implications of climate variability for the detection of multiple equilibria and for rapid transitions in the atmosphere-vegetation system, Clim. Dynam., 38, 1775-1790, 2012.

Bathiany, S., Claussen, M., and Brovkin, V.: $\mathrm{CO}_{2}$-induced Sahel greening in three CMIP5 Earth system models, J. Climate, 27, 7163-7184, 2014.

Baumer, M., Food and Agriculture Organization of the United Nations, and United Nations Environment Programme and Programme on the Ecological Management of Air and Semi-arid Rangelands in Africa and the Near and Middle East of FAO: Notes on Trees and Shrubs in Arid and Semi-arid Regions, Emashar Phase II, Food and Agriculture Organization of the United Nations, Rome, Italy, 1983.

Braconnot, P., Joussaume, S., Marti, O., and de Noblet, N.: Synergistic feedbacks from ocean and vegetation on the African Monsoon response to Mid-Holocene insolation, Geophys. Res. Lett., 26, 2481-2484, 1999.

Braconnot, P., Otto-Bliesner, B., Harrison, S., Joussaume, S., Peterchmitt, J.-Y., Abe-Ouchi, A., Crucifix, M., Driesschaert, E., Fichefet, Th., Hewitt, C. D., Kageyama, M., Kitoh, A., Laîné, A., Loutre, M.-F., Marti, O., Merkel, U., Ramstein, G., Valdes, P., Weber, S. L., Yu, Y., and Zhao, Y.: Results of PMIP2 coupled simulations of the Mid-Holocene and Last Glacial Maximum Part 1: experiments and large-scale features, Clim. Past, 3, 261277, doi:10.5194/cp-3-261-2007, 2007.

Brooker, R. W.: Plant-plant interactions and environmental change, New Phytol., 171, 271-284, 2006.

Brovkin, V. and Claussen, M.: Comment on "Climate-driven ecosystem succession in the Sahara: the past 6000 years", Science, 322, p. 1326, 2008.

Brovkin, V., Claussen, M., Petoukhov, V., and Ganopolski, A.: On the stability of the atmosphere-vegetation system in the Sahara/Sahel region, J. Geophys. Res.-Atmos., 103, 31613-31624, 1998.

Charney, J. G.: Dynamics of deserts and drought in the Sahel, Q. J. Roy. Meteor. Soc., 101, 193-202, 1975.

Claussen, M.: On coupling global biome models with climate models, Clim. Res., 4, 203-221, 1994.

Claussen*, M.: Late Quaternary vegetation-climate feedbacks, Clim. Past, 5, 203-216, doi:10.5194/cp-5-203-2009, 2009. 
Claussen, M. and Gayler, V.: The greening of the Sahara during the Mid-Holocene: results of an interactive atmosphere-biome model, Global Ecol. Biogeogr., 6, 369-377, 1997.

Claussen, M., Brovkin, V., Ganopolski, A., Kubatzki, C., and Petoukhov, V.: Modelling global terrestrial vegetation-climate interaction, Philos. T. R. Soc. B, 353, 53-63, 1998.

Claussen, M., Kubatzki, C., Brovkin, V., Ganopolski, A., Hoelzmann, P., and Pachur, H.-J.: Simulation of an abrupt change in Saharan vegetation in the Mid-Holocene, Geophys. Res. Lett., 26, 2037-2040, 1999.

Claussen, M., Bathiany, S., Brovkin, V., and Kleinen, T.: Simulated climate-vegetation interaction in semi-arid regions affected by plant diversity, Nat. Geosci., 6, 954-958, 2013.

Coe, M. and Bonan, G.: Feedbacks between climate and surface water in northern Africa during the middle Holocene, J. Geophys. Res., 102, 11087-11101, 1997.

Coughenour, M. B. and Ellis, J. E.: Landscape and climatic control of woody vegetation in a dry tropical ecosystem: Turkana District, Kenya, J. Biogeogr., 20, 383-398, 1993.

deMenocal, P., Ortiz, J., Guilderson, T., Adkins, J., Sarnthein, M., Baker, L., and Yarusinsky, M.: Abrupt onset and termination of the African Humid Period: rapid climate responses to gradual insolation forcing, Quaternary Sci. Rev., 19, 347-361, 2000.

Elton, C. S.: Ecology of Invasions by Animals and Plants, Methuen \& Co./Chapman \& Hall, Kluwer Academic Publishers BV, Chicago, 1958.

Francus, P., von Suchodoletz, H., Dietze, M., Donner, R. V., Bouchard, F., Roy, A.-J., Fagot, M., Verschuren, D., and Kröpelin, S.: Varved sediments of Lake Yoa (Ounianga Kebir, Chad) reveal progressive drying of the Sahara during the last 6100 years, Sedimentology, 60, 911-934, 2013.

Hansen, M., DeFries, R., Townshend, J. R., Carroll, M., Dimiceli, C., and Sohlberg, R.: 2001 percent tree cover, in: Vegetation Continuous Fields MOD44B, University of Maryland, College Park, Maryland, 2007.

Hély, C., Bremond, L., Alleaume, S., Smith, B., Sykes, M. T., and Guiot, J.: Sensitivity of African biomes to changes in the precipitation regime, Global Ecol. Biogeogr., 15, 258-270, 2006.

Hély, C., Braconnot, P., Watrin, J., and Zheng, W.: Climate and vegetation: simulating the African humid period, CR Geosci., 341, 671-688, 2009.

Hély, C., Lézine, A.-M., and contributors, APD: Holocene changes in African vegetation: tradeoff between climate and water availability, Clim. Past, 10, 681-686, doi:10.5194/cp-10-681-2014, 2014.

Hoelzmann, P., Jolly, D., Harrison, S. P., Laarif, F., Bonnefille, R., and Pachur, H.-J.: Mid-Holocene land-surface conditions in northern Africa and the Arabian Peninsula: a data set for the analysis of biogeophysical feedbacks in the climate system, Global Biogeochem. Cy., 12, 35-51, 1998.

Huntley, B., Bartlein, P. J., and Prentice, I. C.: Climatic Control of the Distribution and Abundance of Beech (Fagus L.) in Europe and North America, J. Biogeogr., 16, 551-560, 1989.

Hutchinson, G.: Concluding remarks, in: Cold Spring Harbor Symposia on Quantitative Biology, Cold Spring Harbor Symposia on Quantitative Biology, 22, 415-427, 1957.

Jeltsch, F., Weber, G. E., and Grimm, V.: Ecological buffering mechanisms in savannas: a unifying theory of long-term treegrass coexistence, Plant Ecol., 150, 161-171, 2000.
Jolly, D., Prentice, I. C., Bonnefille, R., Ballouche, A., Bengo, M., Brenac, P., Buchet, G., Burney, D., Cazet, J.-P., Cheddadi, R., Edorh, T., Elenga, H., Elmoutaki, S., Guiot, J., Laarif, F., Lamb, H., Lezine, A.-M., Maley, J., Mbenza, M., Peyron, O., Reille, M., Reynaud-Farrera, I., Riollet, G., Ritchie, J. C., Roche, E., Scott, L., Ssemmanda, I., Straka, H., Umer, M., Campo, E. V., Vilimumbalo, S., Vincens, A., and Waller, M.: Biome reconstruction from pollen and plant macrofossil data for Africa and the Arabian peninsula at 0 and 6000 years, J. Biogeogr., 25, 1007-1027, 1998.

Krinner, G., Lézine, A.-M., Braconnot, P., Sepulchre, P., Ramstein, G., Grenier, C., and Gouttevin, I.: A reassessment of lake and wetland feedbacks on the North African Holocene climate, Geophys. Res. Lett., 39, L07701, doi:10.1029/2012GL050992, 2012.

Kröpelin, S., Verschuren, D., Lézine, A.-M., Eggermont, H., Cocquyt, C., Francus, P., Cazet, J.-P., Fagot, M., Rumes, B., Russell, J. M., Darius, F., Conley, D. J., Schuster, M., von Suchodoletz, H., and Engstrom, D. R.: Climate-driven ecosystem succession in the Sahara: the past 6000 years, Science, 320, 765 768, 2008.

Kutzbach, J. E.: Monsoon climate of the Early Holocene: climate experiment with the Earth's orbital parameters for 9000 years ago, Science, 214, 59-61, 1981.

Kutzbach, J. E., and Guetter, P. J.: The influence of changing orbital parameters and surface boundary conditions on climate simulations for the past 18,000 years, J. Atmos. Sci., 43, 1726-1759, 1986.

Kutzbach, J. E. and Liu, Z.: Response of the African monsoon to orbital forcing and ocean feedbacks in the Middle Holocene, Science, 278, 440-443, 1997.

Le Houérou, H. (Ed.): Browse in Africa, the Current State of Knowledge, ILCA, Addis Ababa, Ethiopia, 83-100, 1980.

Lézine, A.-M.: Timing of vegetation changes at the end of the Holocene humid period in desert areas at the northern edge of the Atlantic and Indian monsoon systems, CR Geosci., 341, 750759, 2009.

Lézine, A.-M., Zheng, W., Braconnot, P., and Krinner, G.: Late Holocene plant and climate evolution at Lake Yoa, northern Chad: pollen data and climate simulations, Clim. Past, 7, 13511362, doi:10.5194/cp-7-1351-2011, 2011.

Liu, Z., Notaro, M., Kutzbach, J., and Liu, N.: Assessing global vegetation-climate feedbacks from observations, J. Climate, 19, 787-814, 2006a.

Liu, Z., Wang, Y., Gallimore, R., Notaro, M., and Prentice, I. C.: On the cause of abrupt vegetation collapse in North Africa during the Holocene: climate variability vs. vegetation feedback, Geophys. Res. Lett., 33, L22709, doi:10.1029/2006GL028062, 2006 b.

Liu, Z., Wang, Y., Gallimore, R., Gasse, F., Johnson, T., de Menocal, P., Adkins, J., Notaro, M., Prentice, I., Kutzbach, J., Jacob, R., Behling, P., Wang, L., and Ong, E.: Simulating the transient evolution and abrupt change of Northern Africa atmosphere-ocean-terrestrial ecosystem in the Holocene, Quaternary Sci. Rev., 26, 1818-1837, 2007.

MacArthur, R. H.: Fluctuations of animal populations and a measure of community stability, Ecology, 36, 533-536, 1955.

May, R. M.: Stability and complexity in model ecosystems, Princeton University Press, Princeton, New Jersey, 1973. 
McCann, K. S.: The diversity-stability debate, Nature, 405, 228233, 2000.

New, M. H. M. and Jones, P. D.: Representing twentieth century space-time climate variability. Part 1: development of a 1961-90 mean monthly terrestrial climatology, J. Climate, 12, 829-856, 1999.

Pearman, P. B., Guisan, A., Broennimann, O., and Randin, C. F.: Niche dynamics in space and time, Trends Ecol. Evol., 23, 149158, 2008.

Peterson, A. T.: Ecological niche conservatism: a time-structured review of evidence, J. Biogeogr., 38, 817-827, 2011.

Peterson, A. T., Soberon, J., and Sanchez-Cordero, V.: Conservatism of ecological niches in evolutionary time, Science, 285, 1265-1267, 1999.

Pimm, S. L.: The complexity and stability of ecosystems, Nature, 307, 321-326, 1984.

Prentice, I. C. and Jolly, D.: Mid-Holocene and glacial-maximum vegetation geography of the northern continents and Africa, J. Biogeogr., 27, 507-519, 2000.

Rachmayani, R., Prange, M., and Schulz, M.: North African vegetation-precipitation feedback in early and mid-Holocene climate simulations with CCSM3-DGVM, Clim. Past, 11, 175-185, doi:10.5194/cp-11-175-2015, 2015.

Renssen, H., Brovkin, V., Fichefet, T., and Goosse, H.: Holocene climate instability during the termination of the African humid period, Geophys. Res. Lett., 30, 1184, doi:10.1029/2002GL016636, 2003.

Ritchie, J. and Haynes, C.: Holocene vegetation zonation in the eastern Sahara, Nature, 330, 645-647, 1987.

Sankaran, M. and McNaughton, S. J.: Determinants of biodiversity regulate compositional stability of communities, Nature, 401, 691-693, 1999.

Sankaran, M., Hanan, N. P., Scholes, R. J., Ratnam, J., Augustine, D. J., Cade, B. S., Gignoux, J., Higgins, S. I., Le Roux, X., Ludwig, F., Ardo, J., Banyikwa, F., Bronn, A., Bucini, G., Caylor, K. K., Coughenour, M. B., Diouf, A., Ekaya, W., Feral, C. F., February, E. C., Frost, P. G. H., Hiernaux, P., Hrabar, H., Metzger, K. L., Prins, H. H., T., Ringrose, S., Sea, W., Tews, J., Worden, J., and Zambatis, N.: Determinants of woody cover in African savannas, Nature, 438, 846-849, 2005.

Sarmiento, G.: The Ecology of Neotropical Savannas, Harvard University Press, Cambridge, 1984.

Scheffer, M., Carpenter, S., Foley, J. A., Folke, C., and Walker, B.: Catastrophic shifts in ecosystems, Nature, 413, 591-596, 2001.

Scheffer, M., Bascompte, J., Brock, W. A.,Brovkin, V., Carpenter, S. R., Dakos, V., Held, H., van Nes, E. H., Rietkerk, M., and Sugihara, G.: Early-warning signals for critical transitions, Nature, 461, 53-59, 2009.

Scherer-Lorenzen, M.: Biodiversity and ecosystem functioning: basic principles, in: Biodiversity: Structure and Function, Encyclopedia of Life Support Systems (EOLSS), developed under the Auspices of the UNESCO, edited by: Barthlott, W., Linsenmair, K. E., and Porembski, S., EOLSS Publisher, Oxford, 2005.

Scholes, R. J. and Archer, S. R.: Tree-grass interactions in Savannas, Annu. Rev. Ecol. Syst., 28, 517-544, 1997.
Shelford, V. E.: Animal communities in a temperate America, University of Chicago Press, Chicago, 1913.

Silva, L. C. R., Sternberg, L., Haridasan, M., Hoffmann, W. A., Miralles-Wilhelm, F., and Franco, A. C.: Expansion of gallery forests into central Brazilian savannas, Glob. Change Biol., 14, 2108-2118, 2008.

Spehn, E. M., Hector, A., Joshi, J., Scherer-Lorenzen, M., Schmid, B., Bazeley-White, E., Beierkuhnlein, C., Caldeira, M. C., Diemer, M., Dimitrakopoulos, P. G., Finn, J. A., Freitas, H., Giller, P. S., Good, J., Harris, R., Hogberg, P., Huss-Danell, K., Jumpponen, A., Koricheva, J., Leadley, P. W., Loreau, M., Minns, A., Mulder, C. P. H., O’Donovan, G., Otway, S. J., Palmborg, C., Pereira, J. S., Pfisterer, A. B., Prinz, A., Read, D. J., Schulze, E. D., Siamantziouras, A. S. D., Terry, A. C., Troumbis, A. Y., Woodward, F. I. S., Yachi, S., and Lawton, J. H.: Ecosystem effects of biodiversity manipulations in European grasslands, Ecol. Monogr., 75, 37-63, 2005.

Staver, A. C., Archibald, S., and Levin, S. A.: The Global Extent and Determinants of Savanna and Forest as Alternative Biome States, Science, 334, 230-232, 2011.

Stigall, A. L.: Using ecological niche modelling to evaluate niche stability in deep time, J. Biogeogr., 39, 772-781, 2012.

Tilman, D.: Biodiversity: population versus ecosystem stability, Ecology, 77, 350-363, 1996.

Tilman, D., Knops, J., Wedin, D., Reich, P., Ritchie, M., and Siemann, E.: The influence of functional diversity and composition on ecosystem processes, Science, 277, 1300-1302, 1997.

Vamborg, F. S. E., Brovkin, V., and Claussen, M.: The effect of a dynamic background albedo scheme on Sahel/Sahara precipitation during the mid-Holocene, Clim. Past, 7, 117-131, doi:10.5194/cp-7-117-2011, 2011.

Watrin, J., Lézine, A.-M., Hély, C., Cour, P., Ballouche, D., Elenga, H., Fredoux, A., Guinet, P., Jahns, S., Kadomura, H., Maley, J., Mercuri, A.-M., Pons, A., Reynaud-Farrera, I., Ritchie, J., Salzmann, U., Schulz, E., Tossou, M., Vincens, A., and Waller, M.: Plant migration and plant communities at the time of the "Green Sahara", histoire climatique des déserts d'Afrique et d'Arabie Climatic history of the African and Arabian deserts, CR Geosci., 341, 656-670, 2009.

White, F.: The vegetation of Africa, a descriptive memoir to accompany the UNESCO/AETFAT/UNSO vegetation map of Africa, Natural Resources Research, 20, 1-356, 1983.

Wickens, G. E.: Ecophysiology of Economic Plants in Arid and Semi-Arid Lands, Adaptations of Desert Organisms, Springer, Berlin, Heidelberg, New York, 1998.

Williams, J. W., Shuman, B. N., Webb III, T., Bartlein, P. J., and Leduc, P. L.: Late-quaternary vegetation dynamics in North America: scaling from taxa to biomes, Ecol. Monogr., 74, 309334, 2004.

Williams, J. W., Blois, J. L., and Shuman, B. N.: Extrinsic and intrinsic forcing of abrupt ecological change: case studies from the late Quaternary, J. Ecol., 99, 664-677, 2011. 